\title{
DIVERS@!
}

ISSN 1983-8921

\section{RELATO DE EXPERIÊNCIA: SHANTALA - MASSAGEM PARA BEBÊS- CENTRO DE EDUCAÇÃO INFANTIL ROSA MARIA}

\section{EXPERIENCE REPORT: SHANTALA - MASSAGE FOR BABIES- CHILDHOOD EDUCATION CENTER ROSA MARIA}

\author{
Arlete Ana Motter ${ }^{1}$ \\ Indaiara Felisbino \\ Elisiane Krupniski \\ Ana Paula Micos \\ Tharcila Pazinatto da Veiga ${ }^{2}$
}

\section{Resumo}

Este artigo tem como objetivo relatar a experiência do Projeto de Extensão Universitário denominado "Shantala: massagem para bebês", no período de julho a dezembro de 2010, durante atuação no Centro de Educação Infantil (CEI) Rosa Maria, em Matinhos/PR. As intervenções foram precedidas por três semanas de familiarização com as crianças, que após reunião com os pais, receberam a Shantala duas vezes por semana, sempre pelas mesmas alunas participantes do projeto. Cada criança recebeu em média 15 intervenções. Ao fim do projeto conclui-se que apesar das limitações de infra-estrutura do local e outros pontos de fragilidade, houve predomínio de resultados satisfatórios percebidos pelos pais, cuidadoras e acadêmicas do projeto. Pretende-se dar continuidade ao estudo incluindo orientações para gestantes.

Palavras-chave: criança, massagem, intervenções.

\begin{abstract}
This article aims to report the experience of University Extension Project called "Shantala: massage for babies," which covered the period from July to December 2010, during action in the Early Childhood Center (ERC), Rosa Maria, at Matinhos / PR. The interventions were

Artigo recebido em 24 de março de 2012 e aprovado em 09 de julho de 2012.

${ }^{1}$ Doutora, Professora Adjunto da Universidade Federal do Paraná (UFPR) E-mail: arlete.motter@uol.com.br

${ }^{2}$ Acadêmicas do Curso de Fisioterapia da Universidade Federal do Paraná.
\end{abstract}

Divers@ Revista Eletrônica Interdisciplinar/Matinhos/Vol.5, n.2, p.1-136/jul./dez./2012 


\section{DIVERS@!}

ISSN 1983-8921

preceded by three weeks of familiarization with the children, which after meeting with parents, received Shantala twice a week, always for the same students participating in the project. Each child received an average of 15 interventions. At the end of the project is concluded that despite the limitations of local infrastructure and other aspects quoted as negatives, there were mostly satisfactory outcomes perceived by parents, caregivers and academic project. It is intended to continue the project including guidelines for pregnant women.

Keywords: child, massage, interventions.

\section{Introdução}

A cultura oriental tem difundido mundialmente seus benefícios, trazendo inúmeras contribuições para uma melhor qualidade de vida das pessoas. Além de contribuições como a tradicional medicina indiana e as práticas de massagem, existe ainda a técnica da massagem para bebês, conhecida como Shantala (BERTOLDI e CURVACHO, 2008).

Foi através do obstetra Frances Frederich Leboyer que o ocidente ficou conhecendo a Shantala. Em meados de 1970, durante uma viagem pelo ocidente o médico observou, em Calcutá-Índia, uma mãe massageando seu bebê. Encantado com o vigor e a beleza dos movimentos, batizou a sequência da massagem com o nome da mulher que a realizava Shantala (VICTOR e MOREIRA, 2004).

A Shantala é uma técnica para massagem em bebês, composta por movimentos realizados suave e lentamente no corpo nu da criança, que fica sobre o colo da mãe, permitindo assim ampliar e desenvolver o vínculo entre a mãe e o bebê (MAZON e ARAUJO, 2002). Além de ser uma massagem preventiva, restabelece o aconchego do ventre e a ligação direta com a mãe (LIMA, 2004).

A massagem como recurso terapêutico é reconhecida como uma das terapias mais eficazes para alívio de dores e prevenção de doenças. Tem como proposta de trabalho, através de uma visão holística, tornar o indivíduo consciente do seu corpo como um todo, das suas tensões, da sua respiração e das suas cargas emocionais, além de melhorar a nutrição dos 


\section{DIVERS@!}

ISSN 1983-8921

tecidos pelo aumento da circulação sanguínea e linfática e outros benefícios físicos e emocionais (SEUBERT e VERONESE, 2008).

Os benefícios da massagem em bebês só tornaram-se conhecidos há pouco tempo, porém hoje se sabe que a massagem estimula diretamente os sistemas músculo esquelético, nervoso e circulatório, afetando assim os processos bioquímicos e fisiológicos regulados por estes sistemas (BRÊTAS e SILVA, 1998). Nesse sentido, a massagem Shantala é uma sequência que estimula automaticamente vários pontos, de tal forma que se consegue influenciar beneficamente todos os órgãos do corpo de uma criança, harmonizando-os ou ativando-os (VICTOR e MOREIRA, 2004).

Segundo Seubert e Veronese (2008), a massagem é uma das formas de dar maior sensibilização à pele após o nascimento do bebê, além de integrar a criança com sua mãe (SEUBERT e VERONESE, 2008).

O contato físico, além de ser um sinal de afeto e intimidade, de tranquilizar e estimular o desenvolvimento do indivíduo em vários aspectos é uma necessidade biológica primária (MONTAGU, 1988). Os bebês que recebem toque materno mostram-se mais seguros e mais capazes de lidar adequadamente com situações novas. Até os dois anos de idade, a aprendizagem conta com o movimento, que combinado ao contato físico e ao afeto, potencializa o desenvolvimento, influenciando diretamente o cérebro, e consequentemente a aprendizagem, reforçando a ideia de que o aprendizado sofre influências da estimulação sensorial (LIMA, 2004).

Há um consenso entre os autores Auckett (1983), Leboyer (1986), Nielsen (1989) e McClure (1996) a respeito das vantagens da aplicação de massagens em bebês, pois segundo eles as técnicas trazem benefícios nos aspectos físicos, emocionais e psíquicos dos padrões motores fundamentais das crianças (BRÊTAS e SILVA, 1998).

A massagem em bebês proporciona alivio contra cólicas, acalma e relaxa o bebê, além de reforçar o vinculo mãe-filho, através do contato físico que proporciona (SATO e NASCIMENTO, 2000). Os efeitos da massagem na criança, tanto fisiológicos quanto 


\section{DIVERS@!}

ISSN 1983-8921

comportamentais, são profundos, tornando-o um ser humano capaz de viver em sociedade e manter um contato saudável com as pessoas (MONTAGU, 1988).

A Shantala proporciona a estimulação cutânea e o desenvolvimento psicomotor da criança. O toque estimula ainda a pele, que produz enzimas necessárias à síntese proteica. Leva também à produção de substâncias que ativam a diferenciação de linfócitos $\mathrm{T}$, responsáveis pela imunidade celular, além de diminuir os níveis das catecolaminas (epinefrina, norepinefrina e cortisol) e ativar a produção de endorfinas (neurotransmissores responsáveis pelas sensações de alegria e de bem estar). Em consequência, a criança fica mais relaxada, o sono fica mais calmo e profundo, a amamentação é facilitada, as cólicas diminuem e o vínculo mãe e filho é ampliado (VICTOR E MOREIRA, 2004). A Shantala estimula a digestão, a respiração, proporciona maior contato entre pais e bebê, aumenta os laços familiares, relaxa o bebê e o torna mais calmo e menos agressivo (CRUZ E CAROMANO, 2005). Além dos benefícios físicos, a Shantala ainda pode provocar momentos de paz, amor e ternura, promovendo também o equilíbrio energético entre o bebê e o universo (MAZON E ARAUJO, 2002).

A técnica, por oferecer um estímulo neurológico, possibilita também um desenvolvimento acelerado da criança, além de maior progresso alimentar e motilidade gástrica (associada à melhor digestão e assimilação de alimentos), menor stress frente a estímulos dolorosos, além de cicatrização mais rápida de feridas, efeitos analgésicos e aumentar os padrões de descanso e sono (VERONESE, 2009).

Pesquisas realizadas no Instituto de Pesquisa do Toque na Faculdade de Medicina da Universidade de Miami comprovam os efeitos benéficos do toque para a saúde de bebês prematuros, que ganham $47 \%$ mais peso que os bebês da mesma idade com a mesma ingesta calórica, além de ficar aproximadamente seis dias a menos em internação hospitalar e melhor temperamento nas dimensões da sociabilidade e da confortabilidade (VICTOR E MOREIRA, 2004).

A Shantala não deve ser aplicada quando o bebê apresentar febre, pois a massagem ativa a circulação, podendo elevar a temperatura, ou quando a criança apresentar diarréia, uma 


\section{DIVERS@!}

ISSN 1983-8921

vez que o efeito relaxante da massagem pode intensificar este estado (BRÊTAS e SILVA, 1998). O bebê deve ser conquistado durante cada massagem. Ao aplicar a Shantala, deve-se olhá-lo nos olhos, sorrir, conversar, estar presente. Assim, a massagem será muito mais que uma técnica e aprimorará a comunicação, criando e fortalecendo o vinculo afetivo (BRÊTAS e SILVA, 1998).

\section{Desenvolvimento}

O projeto de extensão "Shantala: massagem para bebês" iniciou-se em março de 2009, na Universidade Federal do Paraná - Setor Litoral. Está registrado na PROEC sob número 535, e aprovado pelo Comitê de Ética em Pesquisa do Setor de Ciências da Saúde/UFPR, sob número 777.112.09.08. Inicialmente foram desenvolvidas atividades visando divulgação da técnica Shantala para mães e cuidadoras de CEI de Matinhos/PR. Em cada oficina, além da palestra e demonstração da técnica, também era distribuído material educativo para pais e cuidadores. Após um semestre de palestras sobre a técnica, no CEI Trem da Alegria, por demanda da direção da escola e dos pais e por interesse das acadêmicas participantes do projeto, foi realizado um semestre de intervenções na mesma escola. Cada criança passou a receber duas intervenções por semana (totalizando 8 sessões), sempre da mesma acadêmica. Resultados com os relatos dessa experiência foram publicados na Revista Extensão em Foco (MOTTER et al, 2010).

Este artigo apresenta o relato de experiência do projeto de extensão relativo ao segundo semestre de 2010, fruto de intervenções realizadas no CEI Rosa Maria, Matinhos/PR. Participaram quatro estudantes do Curso de Fisioterapia da Universidade Federal do Paraná Setor Litoral, de diferentes períodos, orientadas pela Coordenadora do Projeto, Profa. Dra. Arlete Ana Motter. Foram submetidas à técnica Shantala 9 crianças, com média de idade de dezesseis meses, (6 do sexo masculino e 3 do sexo feminino) que receberam em média 15 intervenções. 


\section{DIVERS@!}

ISSN 1983-8921

Precedendo as intervenções, foram realizados encontros com os pais das crianças, para esclarecer a eles sobre o projeto, explicar os efeitos e benefícios da massagem Shantala e a forma como seriam realizadas as intervenções nos bebês. Nesta ocasião foi entregue a cartilha com os passos ilustrados da Shantala, bem como a descrição de cada movimento. O passo a passo da técnica foi demonstrado em uma boneca, uma vez que ainda não havia familiarização com as crianças, o que dificultaria o contado com as mesmas. Ao final do encontro era explicado o Termo de Consentimento Livre e Esclarecido e havendo concordância em participar do estudo, o pai ou responsável assinava o termo.

Na semana posterior à reunião com os pais, iniciou-se à familiarização com as crianças que participariam do estudo. Esta etapa durou três semanas. Durante este período as alunas interagiram com todas as crianças do berçário I do CEI Rosa Maria, de forma que todas as integrantes do projeto tiveram contato direto com todas as crianças. Apenas ao fim das três semanas é que foi definido que aluna atenderia determinadas crianças, pois foi notório com qual aluna cada criança se sentia mais à vontade.

Antes de dar início às intervenções, foi realizada avaliação inicial de cada criança. Na avaliação questionava-se sobre antecedentes gestacionais, estado atual de saúde e desenvolvimento motor, entre outros. Após as intervenções (média de 15), as crianças foram reavaliadas com praticamente os mesmos dados que constavam na ficha de avaliação inicial. Além da avaliação e reavaliação, as alunas foram orientadas a anotar suas percepções sobre cada intervenção realizada com cada participante do projeto.

Cada acadêmica do projeto aplicou a Shantala em duas a três crianças (individualmente), duas vezes por semana. As intervenções foram realizadas, em sua maior parte, no refeitório do CEI. O local era arejado e razoavelmente amplo, podendo ser utilizado por todas as acadêmicas ao mesmo tempo. Havia colchonetes de berço à disposição para maior conforto de acadêmicas e bebês.

Para preservar a imagem das crianças que participaram do estudo, foram usados nomes fictícios para relatar a experiência do projeto. A partir das anotações de cada aluna extensionista, surgiram as opiniões e observações a respeito da experiência. 


\section{DIVERS@!}

ISSN 1983-8921

\section{Aspectos positivos}

Desde o primeiro momento, na reunião com pais e cuidadores, todas as integrantes do projeto foram bem recepcionadas. Direção, pais, zeladoras e cuidadoras foram sempre receptivas, carinhosas e dispostas a atender às necessidades do projeto. As crianças, na grande maioria, também foram bem receptivas e mostravam gostar da presença das alunas.

“[...] Colocaram-se a disposição para o que fosse necessário e sempre que solicitei algo junto a elas, fui atendida prontamente.” (Aluna 1)

"Víamos a alegria delas logo quando abríamos o portão do CEI. Já estavam na janela a nos esperar... rs". (Aluna 2)

$\mathrm{O}$ interesse dos pais em participar do projeto foi bem maior se comparado à experiência anterior no CEI Trem da Alegria, porém quando perguntados sobre a aplicação da massagem em casa, a grande maioria reconheceu não o fazer, alegando como principal motivo a falta de tempo. Ainda assim, tanto no primeiro contato com pais quanto nas demais vezes que as alunas os encontravam estavam prontos a ouvir o que elas tinham a dizer sobre o andamento das intervenções e sempre solícitos a relatar as mudanças notadas no comportamento de seus filhos.

“[...] ouviram atentos todas as informações que tínhamos a dizer, fato bem diferente da outra CEI.” (Aluna 1)

“A participação dos pais é muito importante, pois quando a técnica é realizada em casa a criança permanece tranqüila e acostumada com o toque, não demonstrando receio com as terapeutas.” (Aluna 2)

Cuidadoras de outras turmas do CEI, além daquelas em que as crianças recebiam a Shantala, mostraram interesse na técnica, pois perceberam sua importância como forma de carinho e atenção às crianças do berçário I. 


\section{DIVERS@!}

ISSN 1983-8921

O toque terapêutico de Shantala proporcionou às crianças afeto, tranqüilidade, carinho e afetividade, além de proporcionar a criação de laços de amizade entre acadêmica, bebê e seus familiares. Os autores VERONESE (2009) VICTOR E MOREIRA(2004) e CRUZ E CAROMANO (2005) afirmam que a massagem Shantala proporciona à criança menor estresse frente a estímulos dolorosos, tem efeitos analgésicos, melhora a qualidade do sono e aumenta os vínculos entre aplicador da massagem e criança que recebe. O vai de encontro ao encontrado neste estudo, de acordo com as falas a seguir.

“Criei um vínculo com os bebês em quem apliquei a Shantala que eu certamente não esperava...” (Aluna 3)

"O Miguel foi meu maior presente nas sessões! Sempre se comportava bem e ficava bem relaxado, chegando a dormir durante uma das sessões... rs.” (Aluna 4)

"A melhor coisa que aconteceu durante as intervenções, foi quando estava aplicando a Shantala em um dos bebês e enquanto eu massageava as costas dela, ela começou a fazer carinho nas minhas pernas.” (Aluna 3)

"[...] ela me via e já corria me abraçar, corria deitar no colchonete antes que eu pedisse, sorria muito durante a intervenção, relaxava, ficava calminha." (Aluna 3)

Cuidadoras e alunas notaram diferenças comportamentais das crianças após as sessões. Além da felicidade e mudança de calmaria no comportamento da criança, como benefício da Shantala houve avanço no desenvolvimento infantil. MONTAGU (1988) relata que a aplicação da técnica em crianças é muito importante, pois as crianças conhecem o mundo através do tato e da visão. Silva e Nascimento (2001) afirmam que a pele é o maior órgão sensorial do corpo humano, e os bebês, cercados por tecidos e líquidos mornos ainda enquanto feto são bastante sensíveis, sendo sua estimulação essencial para o desenvolvimento orgânico e psicológico adequados. VERONESE (2009) afirma que a técnica Shantala, oferece um estimulo neurológico, possibilitando também um desenvolvimento psicomotor acelerado da criança.

“[...] algumas crianças que não andavam começaram a andar, logo concluímos que, as intervenções tiveram aspecto positivo também nessa parte do desenvolvimento." (Aluna 1) 


\section{DIVERS@!}

ISSN 1983-8921

Acredita-se que um dos principais resultados encontrados foi a melhora do vínculo acadêmica-bebê e familiar-bebê, o que é de suma importância, tendo em vista a carência afetiva sofrida por diversas crianças, conforme relato da aluna 3:

"Uma das crianças em que apliquei a Shantala era muito carente (mãe com depressão pós-parto e pai dependente químico, era criada pela bisavó) e acredito que com as intervenções da Shantala pude proporcionar além dos benefícios já sabidos da Shantala, bem estar físico, psicológico e carinho ao bebê.” (Aluna 3)

Como a época do ano era favorável, as crianças puderam ser despidas, mantendo-se apenas a fralda, o que proporcionou maior contato entre acadêmica e bebê além de facilitar o toque terapêutico.

“A aplicação foi excelente, em relação à outra CEI, devido à época do ano (no caso estação verão), pudemos realizar a massagem com as crianças despidas, pois no outro CEI, fatores como barulhos na sala, e a necessidade de realizar a técnica por cima das roupas, atrapalhavam o andamento e o resultado do método.” (Aluna 2)

A evolução das acadêmicas na experiência com a prática da terapia refletiu nos resultados das intervenções. Elas puderam ver na prática os benefícios proporcionados pela Shantala. Os resultados foram percebidos durante as intervenções e em conversas com pais e cuidadores onde eles expunham o desenvolvimento da criança. Com o passar das intervenções, veio o aprimoramento da técnica e consequentemente a evolução dos resultados.

"No início fiquei um pouco apreensiva, com medo de não estar fazendo corretamente os movimentos, mas logo peguei prática e me desenvolvi bem nas sessões.” (Aluna 4)

"Nesta CEI pude realizar a sequência inteira da técnica nas crianças, criando um vinculo com muitas delas." (Aluna 2)

Ver a satisfação dos pais e cuidadores em relação ao trabalho realizado foi também motivador para as alunas.

“[...] quando eu conversava com alguns pais eles se mostravam gratos pelas intervenções, falavam dos resultados que notavam nas crianças, dava um novo animo, um estimulo nas intervenções.” (Aluna 3) 


\section{DIVERS@!}

ISSN 1983-8921

\section{Aspectos negativos (pontos de fragilidades da experiência)}

Apesar da boa recepção e do apreço pela vivência das intervenções, o projeto se deparou com algumas dificuldades como fatores climáticos, falta de assiduidade, ruídos no local de intervenção, higiene precária, desvio de atenção e agitação de algumas crianças.

A experiência do projeto no CEI Rosa Maria ocorreu durante período quente do ano, época em que a incidência de chuvas é mais frequente. Tal fato impediu que as alunas realizassem seu trabalho de forma contínua, pois alguns pais não levavam seus filhos em dias muito chuvosos. Algumas crianças adquiriram problemas de saúde, ocasionando sua falta. Os relatos a seguir ilustram a dificuldade em dar continuidade à massagem após as interrupções:

"Alguns dos bebes faltavam muito no CEI, e isso dificultava muito a elas acostumarem com o ritmo da massagem...” (Aluna 4)

“[...] ficou doente no meio das intervenções, faltou por oito intervenções consecutivas. [...] após esse período de ausência ele não queria mais a massagem, chorava muito, não deixava aplicar a Shantala." (Aluna 3)

Uma das crianças foi excluída do protocolo, pois mudou de CEI, conforme relato da acadêmica:

“[...] faltou mais da metade das sessões e quase ao final do estudo já não encontrei mais a criança no CEI e as cuidadoras relataram que o Valentino havia sido transferido para um CEI mais próximo a casa dele.” (Aluna 4)

O local para a realização da Shantala, refeitório, não era o ideal, pois em dias de muito quentes, chuvosos ou de frio, a falta de infra-estrutura dificultava as intervenções:

“[...] era uma boa opção para dias com clima bom/normal, mas se estivesse muito quente o teto de Eternit deixava o ambiente ainda mais abafado e se estava um pouco frio se tornava ruim, porque entrava vento pelas laterais. Isso dificultava principalmente na hora de decidir em tirar ou não a roupa da criança” (Aluna 2) 


\section{DIVERS@!}

ISSN 1983-8921

O fato do local de intervenção ser entre as salas de aula e demais dependências do CEI, além de ser o local de refeição das crianças, gerava excesso de ruídos e deslocamento de pessoas durante a aplicação da Shantala, o que levava as crianças a um aumento da agitação e déficit de atenção.

“[...] havia pessoas passando de um lugar para outro de vez em quando; isso era o que bastava para a criança que estava recebendo a massagem se distrair. Além disso, a criança também se distraía muito quando outras crianças ocupavam o refeitório na hora do lanche.” (Aluna 3)

As alunas encontraram um meio de evitar esse problema utilizando-se de um lugar alternativo para as intervenções. Quando havia salas de aula disponíveis, estas eram usadas para as intervenções, o que garantia maior privacidade para aluna e bebê. As intervenções que não puderam ser realizadas no refeitório ou salas de aula vazias foram feitas na própria sala do berçário I, o que gerava agitação tanto no bebê que recebia massagem quanto nos que assistiam à sessão.

A higiene precária de algumas crianças foi outro fator desfavorável às intervenções. Apesar do esforço das cuidadoras em manter as crianças limpas, em vários momentos as alunas presenciaram crianças sujas, com coriza, odor forte, etc. Ocorreu de o responsável pela criança não enviar fraldas limpas para serem trocadas, o que causou desconforto em alunas, cuidadoras e bebês. Com o problema da higiene veio a preocupação com lesões de pele que pudessem ser contagiosos. Algumas crianças apresentavam pequenas manchas avermelhadas na pele, levando cuidadoras e acadêmicas a ter maior cuidado com higiene das mãos ao massagear uma criança seguida da outra.

Em relação às crianças, o gênio forte e a agitação excessiva impediram ou dificultaram a realização dos passos da Shantala. "Ele era bravo e chorava muito; praticamente em setenta por cento das sessões.” (Aluna 2). Como forma de driblar essa situação foi necessário improvisar posições, locais e formas de massagear para que a sessão fosse completa. "Chorava durante as sessões, o que me obrigava a parar quando ele não queria ser tocado. 


\section{DIVERS@!}

ISSN 1983-8921

[...] Com ele precisei improvisar, sendo necessário fazer alguns movimentos com ele sentado, pois não parava quieto." (Aluna 2)

\section{Considerações Finais}

Ao fim do estudo foi possível observar a importância da familiarização quando comparado à experiência anterior no CEI Trem da Alegria. Tal contato facilitou a interação acadêmica-bebê, possibilitando uma execução mais eficiente da massagem, gerando melhores resultados. Foi possível ampliar o vínculo e o carinho entre acadêmica e bebês, em especial às crianças mais carentes, que em resposta devolviam este carinho às alunas.

Apesar de algumas dificuldades no decorrer das aplicações da massagem Shantala, a prática no CEI Rosa Maria somou experiência às acadêmicas do Curso de Fisioterapia da UFPR, possibilitando a integração com o conhecimento previamente adquirido nos fundamentos teóricos de sala de aula. Os aspectos positivos se sobressaíram aos negativos, o que conduziu a bons resultados nas intervenções.

Para dar continuidade ao projeto e ao aprendizado pretende-se orientar gestantes sobre os conceitos, benefícios e efeitos proporcionados pela técnica da massagem Shantala para que estejam preparadas e instruídas a realizar a massagem após darem luz.

\section{Referências}

BERTOLDI ME, CURVACHO D. Shantala como facilitador de holding do laço mãe-bebê: o início do amor. In: Encontro Paranaense, Congresso Brasileiro, Convenção Brasil/LatinoAmérica, XIII, VIII, II, 2008. Anais. Curitiba: Centro Reichiano, 2008.

BRÊTAS JRS, SILVA, MGB. Massagem em bebês: um projeto de extensão comunitária. Acta Paul. Enf., São Paulo, v.11, número especial, p. 59-63, 1998. 


\section{DIVERS@!}

ISSN 1983-8921

CRUZ CMV, CAROMANO FA. Características das técnicas de massagem para Bebê. Rev. Ter. Ocup. Univ. São Paulo, v. 16, n. 1, p. 47-53, jan./abr., 2005.

LIMA PLS. Estudo exploratório sobre os benefícios da Shantala em bebês portadores de Síndrome de Down. Dissertação de pós-graduação, 2004.

MAZON K, ARAUJO JCO. Uso da Shantala como técnica terapêutica na melhora do sono, variações de humor e cólicas em bebês. Dissertação Unisul. 2002.

MONTAGU A. Tocar: o significado humano da pele. 3. ed. São Paulo: Ed. Summus, 1988

MOTTER, A.A. et al. Projeto de Extensão Shantala: massagem para bebês. Revista Extensão em Foco, Curitiba, n. 6, p. 93-100, jul./dez. 2010. Editora UFPR.

SATO G, NASCIMENTO MJP. Estímulo ao vínculo mãe e filho através do toque. Rev Enferm UNISA 2000; 1: 59- 62.

SEUBERT F, VERONESE L. A massagem terapêutica auxiliando na prevenção e tratamento das doenças físicas e psicológicas. In: Encontro Paranaense, Congresso Brasileiro, Convenção Brasil/Latino-América, XIII, VIII, II, 2008. Anais. Curitiba: Centro Reichiano, 2008.

VERONESE L. A prática da massagem terapêutica sob a ótica da psicologia corporal. In: Encontro Paranaense, Congresso Brasileiro de Psicoterapias Corporais, XIV, IX, 2009. Anais. Curitiba: Centro Reichiano, 2009.

VICTOR JF, MOREIRA TMM. Integrando a família no cuidado de seus bebês: ensinando a aplicação da massagem Shantala. Acta Scientiarum. Health Sciences Maringá, v. 26, no. 1, p. 35-39, 2004. 